\title{
Degenerated fibroid - a diagnostic challenge
}

\section{Sonal Bhuyar, Bhavana Sontakke, Pooja Mukund Rajbhara*}

\begin{abstract}
Department of Obstetrics and Gynecology, Dr. Panjabrao Deshmukh Memorial Medical College, Amravati,
\end{abstract} Maharashtra, India

Received: 05 October 2016

Revised: 11 November 2016

Accepted: 15 November 2016

\section{*Correspondence:}

Dr. Pooja Mukund Rajbhara,

E-mail: pooja.rajbhara36@gmail.com

Copyright: () the author(s), publisher and licensee Medip Academy. This is an open-access article distributed under the terms of the Creative Commons Attribution Non-Commercial License, which permits unrestricted non-commercial use, distribution, and reproduction in any medium, provided the original work is properly cited.

\begin{abstract}
Leiomyoma of the uterus is the most common type of tumor affecting the female pelvis and arises from uterine smooth muscle. The size of leiomyoma varies from microscopic to giant; giant myoma is exceedingly rare. We report an unusual case of a large, cystic, uterine leiomyoma mimicking a primary malignant ovarian tumor on sonography and CT. A 39 year old infertile nulliparous woman presented with a history of lump in abdomen since 2 years and 6 months of amenorrhea. Sonography and CT examination showed a large mass that filled the abdomen. A preoperative diagnosis of a primary malignant ovarian tumor was made. The patient underwent laparotomy with total abdominal hysterectomy preserving tubes and ovaries. The histology revealed a leiomyoma with extensive hyaline degeneration. The current established management of uterine fibroids may include expectant, surgical, or medical management or uterine artery embolization or a combination of these treatments. A surgical approach is preferred for management of giant leiomyomas. Leiomyomas should be considered in the differential diagnosis of a multilocular and predominantly cystic adnexal mass.
\end{abstract}

Keywords: Fibroid, Hyaline degeneration, Leiomyoma of the uterus, Tumor

\section{INTRODUCTION}

A leiomyoma or fibroid is a benign mesenchymal tumour presenting as the most common uterine neoplasm with a prevalence of $20 \%-30 \%$ in the women of reproductive age group. ${ }^{1}$ The size of leiomyomas varies from microscopic to giant. Giant myomas are exceedingly rare. ${ }^{2}$ Most patients with fibroid are asymptomatic, but they may present with infertility, abnormal uterine bleeding, pain or palpable mass. As fibroids enlarge, they outgrow their blood supply causing various types of degeneration, most commonly hyaline (60\%), cystic $(4 \%)$, red $(3 \%)$, calcareous $(4 \%)$ or sarcomatous degeneration $(0.1-0.8 \%) .^{3-7}$ The typical clinical findings and ultrasonography appearance of a uterine fibroid are obscured by the degenerative changes. This report exemplifies how misleading the diagnosis could be with the fibroid degeneration. This was the case of a large uterine fibroid with hyaline degeneration mimicking a neoplastic ovarian mass.

\section{CASE REPORT}

A 39 year old infertile woman married since 15 years came to gynaec OPD on $7^{\text {th }}$ June 2016 with complaints of lump in abdomen which had been increasing gradually since 2 years. She had regular menstrual cycles with average flow followed by amenorrhoea for 6 months. General examination findings were normal. Abdominal examination revealed a 28 weeks mass arising from pelvis, firm to cystic in consistency and was mobile and non-tender on palpation. Per speculum and vaginal examination could not be done due to patient's refusal for the same. Pre-operative profile was within normal limits. Tumour marker estimations showed normal CA-125 and CEA raised slightly to $7.8 \mathrm{ng} / \mathrm{ml}$. Ultrasound examination 
was suggestive of a large echocomplex mass with intermittent cystic areas seen occupying the whole abdomen; uterus and bilateral ovaries could not be imaged separately due to the large mass, hence the possibility of ovarian mass could not be ruled out completely. To confirm the diagnosis and to rule out malignancy, CT scan was advised which suggested a well-defined large complex mass lesion in peritoneal cavity measuring 19.8 x $10.4 \mathrm{~cm}$ most likely ovarian mass. The lesion started just above the bladder and extended up to sub hepatic space occupying both lumbar and iliac region. The mass showed heterogeneous post contrast enhancement. Aorta and IVC were in posterior relation to mass lesion. The mass is in close contact with ascending colon and right psoas muscle. Liver, gall bladder, spleen, both kidneys are normal

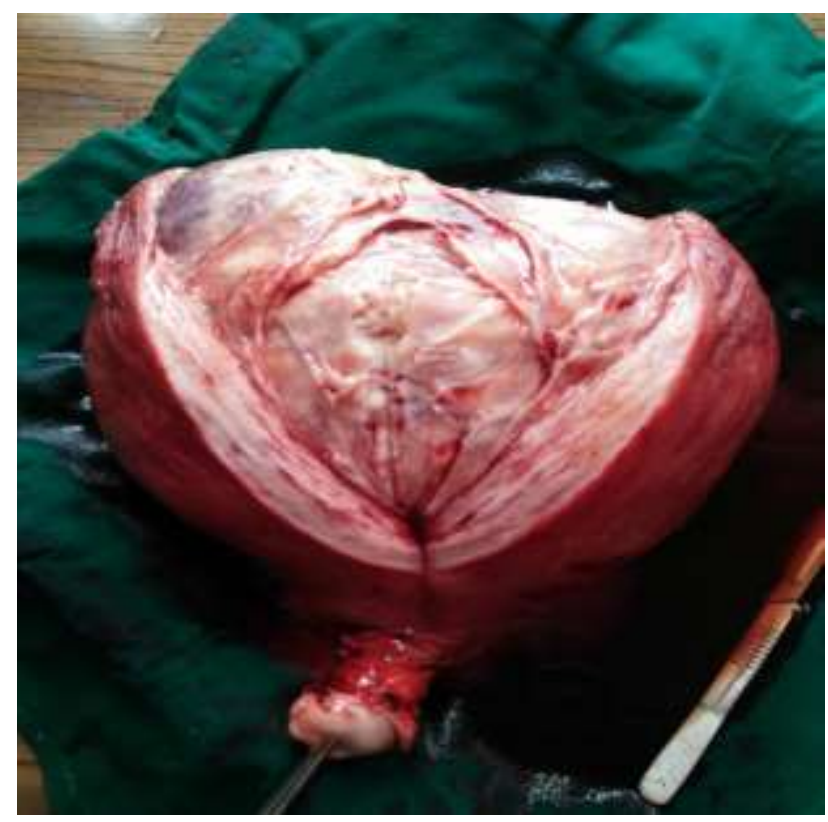

Figure 1: Cut section of the specimen.

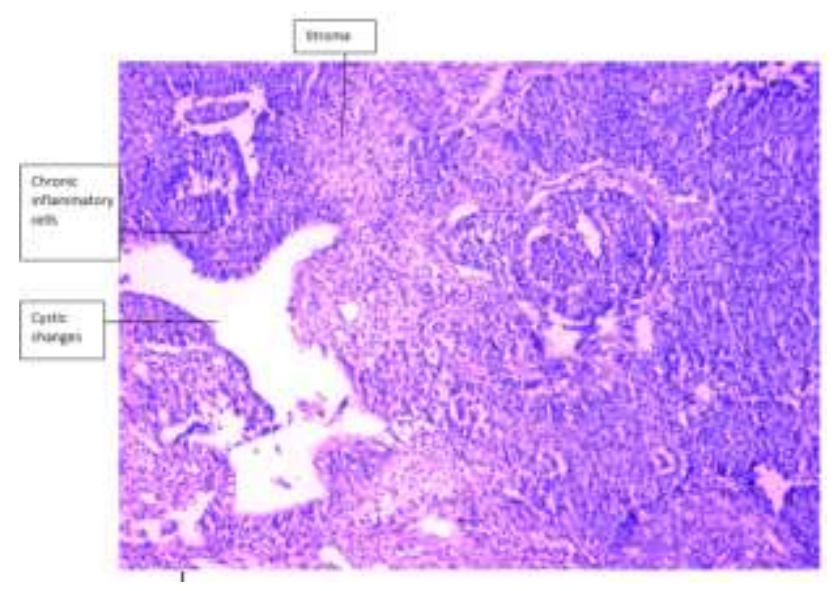

Figure 2: Haematoxylin and eosin stained slide of specimen of cystic degenerated leiomyoma.

Keeping in the view the age of the patient, the large ovarian mass and no associated menstrual complaints, decision for exploratory laparotomy was taken on 11/6/16 with a plan to remove the ovarian tumor and conserve the uterus and contralateral adnexa. But surprisingly intraoperative findings revealed a uniformly enlarged uterus of size $20 \times 15 \mathrm{~cm}$ with cystic consistency and bilateral adnexa normal. Due to the immense size of the tumour and the fibroid being majorly intramural; abdominal hysterectomy was decided and consent of relatives was taken accordingly. Total abdominal hysterectomy was performed and bilateral ovaries were conserved. Post-operative period was uneventful and the patient was discharged on $8^{\text {th }}$ day. Histopathological examination report confirmed leiomyoma with hyaline degeneration and endometrium showing simple hyperplasia.

\section{DISCUSSION}

Leiomyoma or fibroids are composed of smooth muscle surrounded by a pseudo capsule. These are characterised by their location: submucosal, intramural or subserosa which may simulate adnexal masses. As fibroids grow, they outgrow their blood supply causes degeneration, most commonly hyaline, myxoid, cystic, or red degeneration. ${ }^{8,9}$ Ultrasonography is the preferred imaging modality due to its non- invasiveness and costeffectiveness. ${ }^{10} \mathrm{~A}$ fibroid is usually characterized by a concentric, solid, heterogeneous hypoechoic or hyperechoic uterine mass; but the appearance can be variable depending on the amount of fibrous tissue or calcification, with degenerative changes posing a definite diagnostic challenge. ${ }^{11-14}$

Also ultrasound may not be able to dissect the details needed for differentiation between a large uterine and ovarian mass because of many factors, such as a limited field of view and inability to view relationship of a large mass with the uterus and ovary to determine its origin. CT scan cannot distinguish between healthy myometrium and leiomyoma, unless they are calcified or necrotic. MRI can define the anatomy of the uterus and ovaries clearly but its cost limits its use. ${ }^{15}$ In our case also, ultrasound and CT scan were unable to differentiate between the uterine fibroid with degeneration and ovarian mass misleading the preoperative diagnosis of the case. Because degenerated fibroids are great mimics, knowledge of differential diagnosis and their sonographic appearance is important as it may affect the treatment.

\section{CONCLUSION}

Although fibroids usually have a characteristic sonographic appearance, degenerating fibroids can have variable patterns and pose a diagnostic challenge. A uterine leiomyoma with extensive cystic degeneration can masquerade as an ovarian tumour. MRI may be helpful in complicated cases but should not be used indiscriminately. 
Funding: No funding sources

Conflict of interest: None declared

Ethical approval: Not required

\section{REFERENCES}

1. Novak ER, Woodruff JD. Myoma and other benign tumours of the uterus.In: Novak ER, Woodruff JD, editors. Novak's Gynaecology and Obstetric Pathology. Philadelphia: WB Saunders. 1979:26079.

2. Courbiere B, Carcopino X. Gynecologie Obstetrique. Vernazobres-Greco; 2006-2007. Fibromes uterins; pp. 359-365.

3. Okizuka H, Sugimura K, Takemori M, Obayashi C, Kitao M, Ishida T. MR detection of degenerating uterine leiomyomas. J Comput Assist Tomogr. 1993; 17:760-6.

4. Ueda H, Togashi K, Konishi I, Kataoka ML, Koyama T, Fujiwara T, et al. Unusual appearances of uterine leiomyomas: MR imaging findings and their histopathologic backgrounds. Radiographics. 1999;19 Spec No:S131-45.

5. Kawakami S, Togashi K, Konishi I, Kimura I, Fukuoka M, Mori T, et al. Red degeneration of uterine leiomyoma: MR appearance. J Comput Assist Tomogr. 1994;18:925-8.

6. Ueda H, Togashi K, Konishi I, Kataoka ML, Koyama T, Fujiwara T, Kobayashi H, Fujii S, Konishi J. Unusual appearances of uterine leiomyomas: MR imaging findings and their histopathologic backgrounds. Radiographics. 1999;19:131-5.
7. Janus C, White M, Dottino P. Uterine leiomyosarcoma-magnetic resonance imaging. Gynecol. Oncol. 1989;32(1):79-81.

8. Murase E, Siegelman ES. Uterine leiomyomas: histopathologic features, MR imaging findings, differential diagnosis, and treatment. 1999;19(5).

9. Clement PB, Young RH. Diffuse, perinodular, and other patterns of hydropic degeneration within and adjacent to uterine leiomyomas. Am J Surg Pathol. 1992;16(1):26-32.

10. Wladimiroff J. Ultrasound in obstetrics and gynaecology. Elsevier; 2009. Uterine fibroids.

11. Yarwood RL, Arroyo E. Cystic degeneration of a uterine leiomyoma masquerading as a postmenopausal ovarian cyst: a case report. J Reprod Med. 1999;44:649-52.

12. Reddy NM, Jain K, Gerscovich EO. A degenerating cystic uterine fibroid mimicking an endometrioma on sonography. J Ultrasound Med. 2003;22:973-6.

13. Cohen JR, Luxman D, Sagi J, Jossiphov J, David MP. Ultrasonic "honeycomb" appearance of uterine submucous fibroids undergoing cystic degeneration. J Clin Ultrasound. 1995;23:293-6.

14. Salvo DN. Sonographic imaging of maternal complications of pregnancy. J Ultrasound Med. 2003;22:69-89.

15. Casillas J, Joseph RC, Guerra JJ. CT appearance of uterine leiomyomas. Radiographics. 1990;10(6):9991007.

Cite this article as: Bhuyar S, Sontakke B, Rajbhara PM. Degenerated fibroid - a diagnostic challenge. Int J Reprod Contracept Obstet Gynecol 2017;6:292-4. 